\title{
Effect of application of peer learning strategy on obstetric and gynecological nursing students' clinical performance
}

\author{
Rasha Mohamed Essa*1, Jilan Ibrahim Al-Battawi ${ }^{2}$, Doaa Ali Abd El Salam El demerdash ${ }^{1}$, Hend Abo Elsoud Ahmed ${ }^{1}$ \\ ${ }^{1}$ Faculty of Nursing, Damanhour University, Damanhour, Egypt \\ ${ }^{2}$ Faculty of Nursing, University of Alexandria, Alexandria, Egypt
}

Received: September 12, 2017

Accepted: November 6, 2017

Online Published: November 24, 2017

DOI: $10.5430 /$ jnep.v8n3p144

URL: https://doi.org/10.5430/jnep.v8n3p144

\begin{abstract}
Background and objective: Peer learning is an efficient educational technique for nursing students. It equips them up for their future roles as instructors, promotes their psychomotor skills, and establishes their self-esteem. The current study aims to determine the effect of application of peer learning strategy on obstetric and gynecological nursing students' clinical performance. Methods: Quasi-experimental design was utilized. The study was carried out in the obstetric and gynecology skills lab at the Faculty of Nursing, Damanhour University, Albehera Governorate. It comprised a purposive sample of 160 undergraduate nursing students, enrolled in the Obstetric and Gynecology Nursing Department (second semester of the third year in academic year 2014-2015). They were equally randomly assigned to either one of two groups, intervention group (80) and control group (80). Three tools were used: First, a personal and academic questionnaire sheet. Second, students' performance observational checklist. Third, student feedback and satisfaction questionnaire.

Results: It was shown that there was a statistically significant difference in clinical performance scores concerning the five tested clinical obstetric and gynecological procedures among the intervention and control group, where the intervention group was more satisfied and have positive feedback than the control group.

Conclusions: Peer learning strategy is an efficient strategy in the improvement of nursing students' performance than traditional learning. The study recommended that implementation of peer learning strategy in clinical setting to increase the level of students' knowledge and clinical performance.
\end{abstract}

Key Words: Peer learning, Student performance, Satisfaction

\section{INTRODUCTION}

Learning is a process that results in some relatively permanent modifications. Specifically in: the way of thinking, feeling and learner's doings. Accordingly, it must be an emancipator technique. There must be an atmosphere of trust and freedom to reflect, discuss, question, compare, creative, discover, be self-directed, empower and to hold accountable.
Because learning is individual and unique for each learner, teachers must be flexible, problem-solvers, critical thinkers, reflective, and above all cooperative in order to build the proper climate for learning. ${ }^{[1]}$

It is a challenge for a nurse educator to create innovative paradigms in nursing pedagogy which enhance students' creativity, capabilities and motivation. Innovative educational

*Correspondence: Rasha Mohamed Essa; Email: rashaessa111@yahoo.com; Address: Faculty of nursing, Damanhour university, Egypt. 
strategies provide opportunities for students to professionally function in cooperative relationships with their peers. In turn, this will be reflected on the quality of the graduates' performance by providing comprehensive, systematic, and continuous, and purposive nursing intervention. The ultimate goal of nursing education programs is to graduate a greater number of competent, accountable, and reliable professionals capable of cooperating with one another and other members of the health care team. ${ }^{[2,3]}$

Although science and skills were the hallmark of the trained obstetric and gynecologic nursing student, interactions with the mother-to-be and her family or with female patients also were of great consequence. It was important for the student to establish an effective communication. That put a great struggle on obstetric nursing educators to select active learning strategies that educate the students' knowledge, intellectual, practical, professional as well as general and transferable skills. Those an efficient learning strategies educate students how to analyze and evaluate the pertinence of information and how to apply the information in different settings and situations. ${ }^{[4]}$

More effective student centered learning techniques are currently being used to support active student involvement and creative thinking. One of these strategies is peer learning. It is a method of education in which students help each other and learn through teaching. ${ }^{[5,6]}$ Qermamn (2004) had realized peer learning as: "instructional strategy that partners students to help one another learn material, reinforce skills or practice a learned task". [7]

Peer learning, as acquaint by Topping (2005), is the acquisition of information and skills through active assistance and support among stated equals or matched companions. It is an educational practice in which students react with different students to achieve educational objectives. ${ }^{[5]}$

Peer learning has been utilized in instruction to address cognitive growth, critical thinking, psychomotor skills, clinical aptitudes, and academic gains. In addition, this strategy promotes independent study, and problem solving skills. It could provide students a feeling of independence when they accepted accountability for their own instruction. Furthermore, it enhances the development of learning outcomes, communication skills, teamwork, critical enquiry and reflection, and learning meaningfully. ${ }^{[8,9]}$

Thurston and Topping (2007) considered that peer learning as a method is broadly utilized to enhance attainment in students. Where, learners are stimulated to review, learn, and understand the material when they are place into a teaching role. ${ }^{[9,10]}$ These circumstances make learners more regulated in the working process, supporting each other, and hence guaranteeing that their learning objectives are fulfilled. ${ }^{[11]}$

Tiwari et al. (2006) and Sally (2003) identified key concepts of effective peer learning: First, students are active learners rather than passive participants which in turns will increase their motivation to think and learn as they determine their own learning needs and goals. Second, teacher functions as facilitator rather than instructor, his/her role changes from "Sage on the stage" to "guide on the side". Lastly, the learning environments is one of collaborative group centered learning. ${ }^{[12,13]}$ Review of literature had revealed several beneficial effects of peer learning. Cohen (1994), O’Donnell and King (1999) provide evidence that peer interactions can promote cognitive growth and advancement in performance. ${ }^{[14,15]}$ In addition, study was done by Topping K, Bryce A. (2005) in Scotland, reported that, in peer learning and interaction, student is actively involved in the learning process, acquire knowledge and skills through active helping and supporting among status equals or matched companions. ${ }^{[16]}$ Moreover, Secomb (2008) in Australia, concluded that learning outcomes were enhanced by peer teaching and learning. ${ }^{[17]}$

Professional nurse must have the capability to practice their different roles such as: supervisors, educators, care providers, managers, and researchers. To do so, they should be able to solve clinical problems through analysis, synthesis, critical thinking, and effective communication. Such skills are not anticipated to be provided through conventional education but need an active learning process with peer teaching. ${ }^{[18,19]}$

The nursing care in general and care of obstetric and gynecological woman in particular indicates the care performance and its quality. So that, any failure in competencies can be reason for inadequate care as well as increase maternal mortality and morbidity. Therefore, improving nurses' abilities in this field of care for obstetric and gynecological woman is of great importance. Since traditional teaching methods are not suitable for communities with rapid knowledge expansion and constant changes, peer learning technique can be a viable alternative, which is intended to facilitate student learning.

In spite of the fact that the utilization of active and cooperative instruction methods has been related to enhanced student learning, these practices require expanded exertion with respect to both faculty and learners. In addition, there are few studies conducted in Egypt about the effect of different learning strategies as peer learning technique in nursing. Therefore, this study was carried out to determine the effect of application of peer learning strategy on obstetric and gynecological nursing students' clinical performance. 
Hypotheses: Nursing students who are instructed through peer learning strategy exhibit higher clinical performance scores than those who are instructed through traditional teaching method.

\section{MATERials AND METHOD}

\subsection{Design}

A quasi-experimental research design was utilized in this study.

\subsection{Setting}

The study was carried out in the obstetrics and gynecology skills lab at the Faculty of Nursing, Damanhour University.

\subsection{Subject}

The subjects of this study comprised of 160 students. All nursing students, registered in Obstetrics and Gynecologic Nursing course (second semester of the third year in academic year (2014-2015). They were equally randomly assigned to either one for two groups. The intervention group ( $n=80)$ and the control group $(n=80)$. The intervention group used peer learning strategy, where the control group learn with traditional learning strategy.

In clinical practice, nursing students usually distributed and rotated among five clinical rotations including, ante partum, labor and delivery, postpartum, family planning and gynecology sections.

\subsection{Data collection tools}

Three tools were used.

Tool I: A personal and academic questionnaire sheet, which contains information about nursing students' age, sex, previous academic level, previous academic achievement, and years of experiences.

Tool II: Students' performance observational checklist. This tool was prepared by the Obstetric and Gynecological Nursing Department staff, Faculty of Nursing, Damanhour University. This tool was utilized to measure nursing students' performance. It contains 120 items and includes five clinical procedure: abdominal examination during pregnancy (24 items), palpation of uterine contraction (19 items), Fundal assessments during postpartum (14 items), IUD insertion (27 items), and Gynecological examination (36 items). Each point was checked and given a score ranging from (1-3) as follow:

- Correct and completely done (3),

- Correct but incompletely done (2), and

- Wrong or not done (1).

146
The scoring system of total performance ranged from 120 to 360 distributed as follows:

- Poor $<168$,

- Satisfactory $168-<216$,

- Good $216-<264$,

- Very good $264-<312$,

- Excellent $\geq 312$.

The scoring of five procedures were distributed as follows:

1) Abdominal examination during pregnancy: ranged from 24-72 distributed as follows:

- Poor $<34$,

- Satisfactory $34-<44$,

- Good $44-<54$,

- Very Good $54-<64$,

- Excellent $\geq 64$

2) Palpation of uterine contraction: ranged from 19-57, distributed as follows:

- Poor $<27$,

- Satisfactory $27-<35$,

- Good $35-<43$,

- Very good $43-<51$,

- Excellent $\geq 51$.

3) Fundal assessments during postpartum ranged from 14-42, distributed as follows:

- Poor $<20$,

- Satisfactory $20-<26$,

- Good $26-<32$,

- Very good $32-<38$,

- Excellent $\geq 38$.

4) IUD Insertion ranged from 27-81, distributed as follows:

- Poor $<38$,

- Satisfactory $38-<49$,

- Good $49-<60$,

- Very good $60-<71$,

- Excellent $\geq 71$.

5) Gynecological examination ranged from 36-108, distributed as follows:

- Poor $<50$,

- Satisfactory $50-<64$,

- Good $64-<78$,

- Very good $87-<92$,

- Excellent $\geq 92$. 
Tool III: Student feedback and satisfaction questionnaire. This tool was developed by the researchers after reviewing the related literature. It was used to determine students' feedback about the learning method used for developing the nursing skills at the nursing lab. This tool consisted of five questions about: the method preferred to learn nursing skills either traditional or peer, whether the time allowed for training was enough or not, whether the learning method used was effective or not and If not why, and a four points likert scale to reflect the degree of agreement or satisfaction on ten items about the learning method used categorized as: strongly agree, agree, disagree, strongly disagree. Strongly agree and agree, indicate students' satisfaction while disagree and strongly disagree indicate dissatisfaction. A score of one was assigned to strongly agree and a score of four was assigned to strongly disagree.

The maximum score was 40 . Its distribution was as follows: $>20$ scores for satisfaction level and $\leq 20$ scores for dissatisfaction level.

\subsection{Procedures}

An official approval was obtained from responsible authorities and participants after explaining its purpose. Content validity of the tools was tested by a jury of 5 experts in nursing education and obstetrics and gynecology nursing fields and consequently, necessary modifications were done. Tools reliability was checked by Cronbach's Alpha test. Its result was 0.869 for Tool II, and 0.789 for Tool III which indicates an accepted reliability

Pilot study was conducted by the researchers to test the clarity and applicability of the tools on 16 undergraduate nursing students from the first term enrolled in obstetrics and gynecology course (out of the sample). According to the results of the pilot study, the tools were reconstructed and put in its final form.

\subsubsection{Preparation phase}

a) Assessment and preparing the environment: The researchers assessed and obtained data from the student affairs administration related to students' number, age, gender and the last year students' marks. The teaching learning environment was assessed and prepared to check the efficiency of the electric machines, and to check the quality of light, and ventilation.

b) Content preparation: Preparing the intended learning outcomes concerning the content of the selected five clinical skills: abdominal examination during pregnancy, palpation of uterine contraction, Gynecological assessment/examination, IUD Insertion, and Fundal assessment during post partum that cover all clinical rotations.

Published by Sciedu Press c) Educational materials preparation: Instructional materials as handouts of learning materials concerning the five selected skills and videos were provided to the students.

d) Students preparation: A training concerning the tutoring process was conducted to both the intervention group students and the clinical instructors of the obstetrics and gynecology department. The training includes the following points; role of the tutor; the tutor as a helper and the tutor as a "model student", tutor code of ethics, general tutoring tips and techniques, tips for group tutoring, characteristics of successful tutors, active listening strategies, role of the tutees, how students will work together? Then a special session was implemented on how to design a lesson plan.

A total of 16 tutor students were selected randomly from students with higher marks in the previous year and semester.

Tutor students receive concentrated training on the five clinical procedures under supervision of the researchers, then demonstration and re-demonstration on it was supervised by the researchers. Each student was allowed to apply steps of each procedure in the Faculty skill lab under the supervision of the researchers in order to master the skill.

\subsubsection{Implementation phase}

- The 64 students (80-16) in the intervention group were divided one peer tutor to four students in every group for application of the peer learning process.

- The student tutors then designed lesson plans that were revised by the researchers.

- The researchers prepared a schedule for the trained students to act as peer teachers for their colleagues. The clinical sessions started from 8:30 AM to 1:00 PM two days/week for 10 weeks.

- The control group $(\mathrm{N}=80)$ students sub-grouped and distributed to skill labs. These subgroups were trained by clinical instructors in traditional clinical sessions. The clinical sessions started from 8:30 AM to 1:00 PM two days/week for 10 weeks.

\subsubsection{Post test and evaluation phase}

Tool II: Students' Clinical Performance were evaluated by the check lists that distributed among both the intervention and control group. Then Tool III: Students' feedback and satisfaction about the effectiveness of the peer learning strategy was distributed among both group.

\subsection{Ethical considerations}

The researchers obtained the official permissions to conduct the study from the Dean of the Faculty and the head of the Obstetric and Gynecological Department, at the Faculty of Nursing, Damanhour University. 
An individual informed consent was obtained from each student after full explanation of the study objectives and procedures. Students were reassured that participation is totally voluntary, that refusals or withdrawals have no consequences, and that the information would be strictly confidential and does not affect the assessment of their academic achievement.

\section{Results}

Table 1 donates absence of any significant differences between the intervention and control groups in relation to their personal profile. Where, slightly more than one-half $(51.25 \%)$ of the intervention group were males, compared to $40 \%$ of the control group. Around and more than three-fifths among both the intervention (65\%) and control (58.75\%) groups were 19 to less than 21 years. Near to and more than two-thirds $(63.75 \% \& 68.75 \%)$ of students in intervention and control group respectively had secondary school education. Similar proportions $(18.75 \%)$ of both groups have got very good degree and around half of the intervention (48.75\%) and control (50.0\%) groups have got good degree in last year semester.

Table 2 reveals the the Mean percent scores of clinical performance of the intervention group were significantly higher than the control group in the five tested clinical procedures specifically, abdominal examination during pregnancy, palpation of uteine contraction, fundal assessment during postpatrum, gynecological assessment and insertion of IUD.

Table 1. Number and percent distribution of nursing students among the intervention and control groups according to their personal profile

\begin{tabular}{|c|c|c|c|c|c|c|}
\hline \multirow{2}{*}{ Personal profile } & \multicolumn{2}{|c|}{ Intervention $(\mathbf{n}=\mathbf{8 0})$} & \multicolumn{2}{|c|}{ Control $(n=80)$} & \multirow{2}{*}{ Test of sig. } & \multirow{2}{*}{$p$} \\
\hline & No. & $\%$ & No. & $\%$ & & \\
\hline \multicolumn{7}{|l|}{ Gender } \\
\hline Male & 41 & 51.25 & 32 & 40 & \multirow{2}{*}{$\chi^{2}=2.04$} & \multirow{2}{*}{.153} \\
\hline Female & 39 & 48.75 & 48 & 60 & & \\
\hline \multicolumn{7}{|l|}{ Age (years) } \\
\hline $19-<21$ & 52 & 65 & 47 & 58.75 & \multirow{2}{*}{$\chi^{2}=0.66$} & \multirow{2}{*}{.415} \\
\hline$\geq 21$ & 28 & 35 & 33 & 41.25 & & \\
\hline Min.-Max. & \multicolumn{2}{|c|}{$21.0-22.0$} & \multicolumn{2}{|c|}{$21.0-22.0$} & \multirow{2}{*}{$t=.365$} & \multirow{2}{*}{.625} \\
\hline Mean \pm SD & 21.4 & & 21.3 & & & \\
\hline \multicolumn{7}{|l|}{ Previous academic degree } \\
\hline Secondary school & 51 & 63.75 & 55 & 68.75 & \multirow{2}{*}{$\chi^{2}=0.451$} & \multirow{2}{*}{.503} \\
\hline Associate degree in nursing & 29 & 36.25 & 25 & 31.25 & & \\
\hline \multicolumn{7}{|l|}{ Academic achievement } \\
\hline Excellent & 8 & 10 & 3 & 3.75 & \multirow{4}{*}{$\chi^{2}=2.69$} & \multirow{4}{*}{.442} \\
\hline Very good & 15 & 18.75 & 15 & 18.75 & & \\
\hline Good & 39 & 48.75 & 40 & 50 & & \\
\hline Poor & 18 & 22.5 & 22 & 27.5 & & \\
\hline
\end{tabular}

Regarding the palpation of uteine contraction, abdominal examination during pregnancy, and IUD insertion, there was a statistical significant difference in the levels of performance between the intervention and the control group $\left(\chi^{2}=97.26^{*}\right.$, $\left.p<.001, \chi^{2}=87.15^{*}, p<.001 \& \chi^{2}=55.68 *, p<.001\right)$ respectively where, the majority $(91.25 \%, 88.8 \% \& 88.8 \%)$ of the intervention group students got excellent score compared to only $13.8 \% \& 15 \% \& 8.75 \%$ of the control group respectively.

In relation to gynecological assessment, and fundal assessment procedures, Table 2 also reveals that the majority
$(87.5 \% \& 83.8 \%)$ of the intervention group students got excellent score compared to only $6.2 \% \& 15 \%$ of the control group respectively. A statistical significant difference in the score levels of performance existed between the intervention and control group in the two procedures: $\left(\chi^{2}=62.5^{*}, p<\right.$ $.001)$ and $\left(\chi^{2}=39.55^{*}, p<.001\right)$ respectively.

Multivariate analysis of Table 3 clarifies the independent effect of the peer learning strategy on students' performance scores in the five tested clinical procedures. This effect is mainly observed in the Fundal assessment during postpartum explaining $95 \%$ of the variance of this score, and the model 
excluded both age and the previous academic degree. As Furthermore, gynecological assessment explaining $88 \%$ of for the effect in abdominal examination during pregnancy, its variance and the model excluded age. Regarding the effect explaining $91 \%$ of its variance. In addition, in palpation of in IUD insertion, explaining $85 \%$ of its variance and age was uterine contraction explaining $88 \%$ of its variance.

excluded.

Table 2. Comparison between intervention and control group according to their clinical performance

\begin{tabular}{|c|c|c|c|c|c|c|}
\hline \multirow[t]{2}{*}{ Clinical procedures } & \multicolumn{2}{|c|}{$\begin{array}{l}\text { Intervention } \\
(\mathbf{n}=\mathbf{8 0})\end{array}$} & \multicolumn{2}{|c|}{$\begin{array}{l}\text { Control } \\
(\mathrm{n}=\mathbf{8 0})\end{array}$} & \multirow[t]{2}{*}{ Test of sig. } & \multirow[t]{2}{*}{$p$} \\
\hline & No. & $\%$ & No. & $\%$ & & \\
\hline \multicolumn{7}{|c|}{ Score of abdominal examination during pregnancy } \\
\hline Very good $(75 \backslash \%-85 \%)$ & 9 & 11.3 & 68 & 85.0 & \multirow{2}{*}{$\chi^{2}=87.15^{*}$} & \multirow{2}{*}{$<.001 *$} \\
\hline Excellent $(>85 \%)$ & 71 & 88.8 & 12 & 15.0 & & \\
\hline Mean \% score & \multicolumn{2}{|c|}{$95.06 \pm 3.66$} & \multicolumn{2}{|c|}{$82.16 \pm 3.99$} & $t=19.8^{*}$ & $<.001 *$ \\
\hline \multicolumn{7}{|c|}{ Score of palpation of uteine contraction } \\
\hline \multicolumn{7}{|l|}{ Fail $(<60 \%)$} \\
\hline Pass $(60 \%-65 \%)$ & 0 & 0.0 & 20 & 25.0 & \multirow{2}{*}{$\chi^{2}=97.26^{*}$} & \multirow{2}{*}{$<.001 *$} \\
\hline Good $(65 \%-75 \%)$ & 7 & 8.8 & 49 & 61.3 & & \\
\hline Excellent $(>85 \%)$ & 73 & 91.2 & 11 & 13.8 & & \\
\hline Mean \% score & \multicolumn{2}{|c|}{$95.0 \pm 6.11$} & \multicolumn{2}{|c|}{$76.25 \pm 11.21$} & $t=15.9 *$ & $<.001 *$ \\
\hline \multicolumn{7}{|c|}{ Score of Gynecological assessment/examination } \\
\hline Fail $(<60 \%)$ & 0 & 0.0 & 10 & 12.5 & & \\
\hline Pass $(60 \%-65 \%)$ & 1 & 1.2 & 22 & 27.5 & & \\
\hline Good $(65 \%-75 \%)$ & 3 & 3.8 & 40 & 50.0 & $\chi^{2}=62.5 *$ & ${ }^{\mathrm{MC}} p=<.001^{*}$ \\
\hline Very good $(75 \%-85 \%)$ & 6 & 7.5 & 3 & 3.8 & & \\
\hline Excellent $(>85 \%)$ & 70 & 87.5 & 5 & 6.2 & & \\
\hline Mean \% score & \multicolumn{2}{|c|}{$93.22 \pm 7.15$} & \multicolumn{2}{|c|}{$69.11 \pm 11.01$} & $t=14.65^{*}$ & $<.001 *$ \\
\hline \multicolumn{7}{|l|}{ Score of IUD Insertion } \\
\hline Fail $(<60 \%)$ & 0 & 0.0 & 10 & 12.5 & & \\
\hline Pass $(60 \%-65 \%)$ & 0 & 0.0 & 28 & 35 & & \\
\hline Good $(65 \%-75 \%)$ & 5 & 6.2 & 30 & 37.5 & $\chi^{2}=55.68^{*}$ & ${ }^{\mathrm{MC}} p=<.001^{*}$ \\
\hline Very good $(75 \%-85 \%)$ & 4 & 5.0 & 5 & 6.2 & & \\
\hline Excellent $(>85 \%)$ & 71 & 88.8 & 7 & 8.8 & & \\
\hline Mean \% score & \multicolumn{2}{|c|}{$92.18 \pm 9.35$} & \multicolumn{2}{|c|}{$66.22 \pm 11.78$} & $t=9.36^{*}$ & $<.001 *$ \\
\hline \multicolumn{7}{|c|}{ Score of Fundal assessment } \\
\hline Good (65\%-75\%) & 1 & 1.3 & 26 & 32.5 & & \\
\hline Very good (75\%-85\%) & 12 & 15.0 & 42 & 52.5 & $\chi^{2}=39.55^{*}$ & $<.001 *$ \\
\hline Excellent $(>85 \%)$ & 67 & 83.8 & 12 & 15.0 & & \\
\hline Mean \% score & \multicolumn{2}{|c|}{$96.82 \pm 3.88$} & \multicolumn{2}{|c|}{$79.89 \pm 6.11$} & $t=13.6^{*}$ & $<.001 *$ \\
\hline
\end{tabular}

$\chi^{2}:$ Chi square test, MC: Monte Carlo for Chi square test: $t$-test, ${ }^{*}$ Statistically significant at $p \leq .001$

Table 4 exhibits feedback of nursing students in both control and intervention group about learning method used. As regards the best method that the students prefer for learning nursing skills, the table illustrates that more than half of the control group students $(52.5 \%)$ prefer traditional learning method to learn nursing skills, while the majority of the intervention group students $(97.5 \%)$ prefer peer learning method to learn nursing skills.

Table 4 also reveals that the majority of the control group (80\%) mentioned that the time allocated for clinical training wasn't enough, while all nursing students in the intervention $(100 \%)$ mentioned that the time was enough. Concerning the effectiveness of the learning method used, it was observed that more than half of the control group mentioned that, the 
method was effective for learning nursing skills compared with $100 \%$ of the intervention. Among those of the control group there were students who mentioned that the learning method used was not effective, they stated that there was lack of time, limited re-demonstration, and limited feedback
(10\%, 30\%, and $20 \%$ respectively).

Table 5 reflects students' satisfaction regarding traditional and peer learning methods used for both control and intervention groups.

Table 3. Best fitting multiple linear regression model for nursing students' performance scores

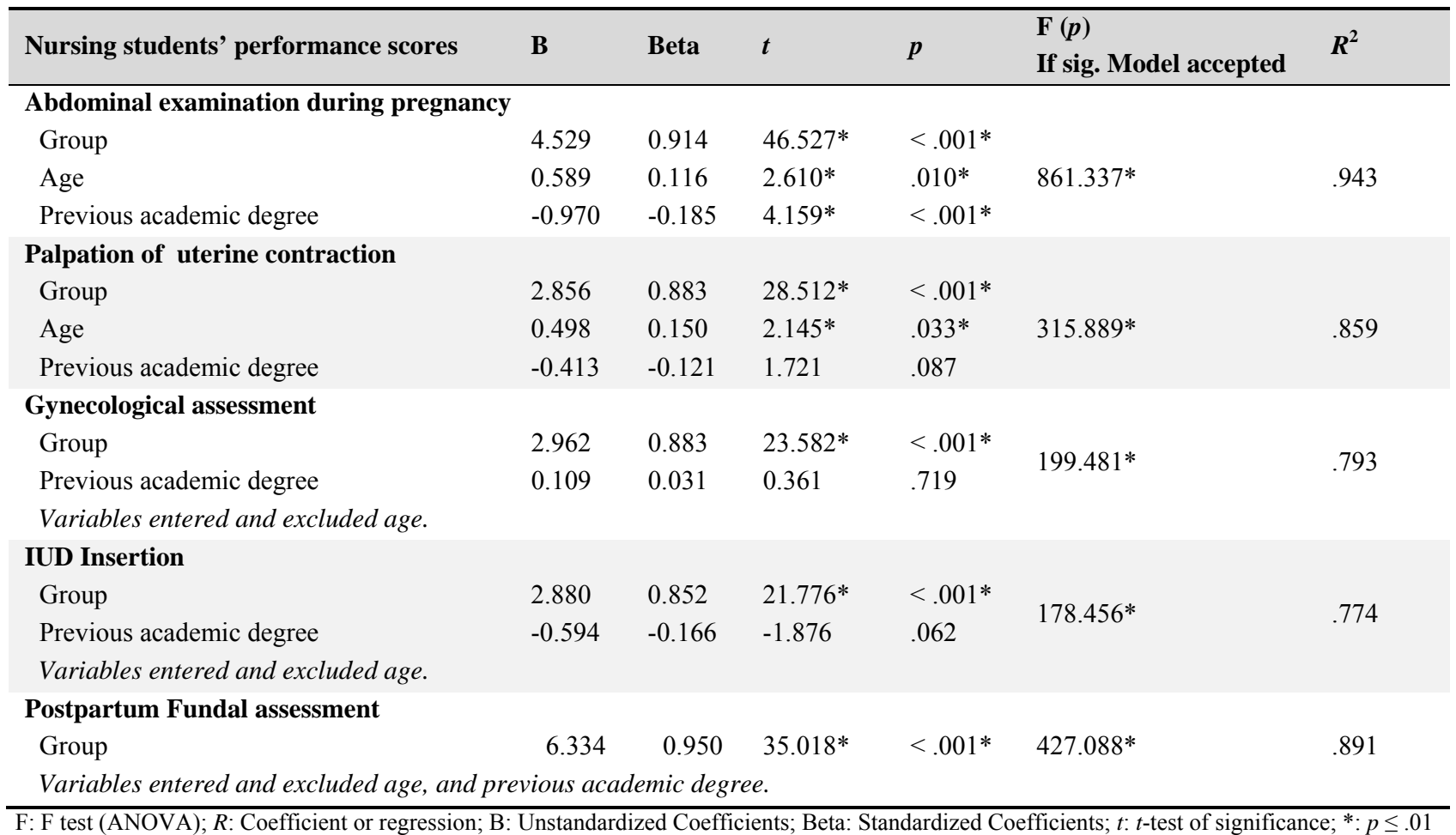

Table 4. Feedback of nursing students in both control and intervention group about learning methods used

\begin{tabular}{|c|c|c|c|c|}
\hline \multirow{2}{*}{$\begin{array}{l}\text { Learning method used } \\
\text { The best method you prefer to learn nursing skills }\end{array}$} & \multicolumn{2}{|c|}{$\begin{array}{l}\text { Intervention group } \\
(\mathbf{n}=\mathbf{8 0})\end{array}$} & \multicolumn{2}{|c|}{$\begin{array}{l}\text { Control group } \\
(\mathbf{n}=\mathbf{8 0})\end{array}$} \\
\hline & & & & \\
\hline Traditional learning method & 2 & 2.5 & 42 & 52.5 \\
\hline Peer learning method & 78 & 97.5 & 38 & 47.5 \\
\hline \multicolumn{5}{|l|}{ Time allowed for training was } \\
\hline Enough & 80 & 100 & 16 & 20.0 \\
\hline Not enough & 0 & 0 & 66 & 80.0 \\
\hline \multicolumn{5}{|c|}{ The learning method used is considered an effective method to learn nursing skills } \\
\hline Yes & 80 & 100 & 42 & 52.5 \\
\hline No & 0 & 0 & 38 & 47.5 \\
\hline \multicolumn{5}{|c|}{ Student who said no, state why?* } \\
\hline Lack of time & 0 & 0 & 8 & 10 \\
\hline No re-demonstration & 0 & 0 & 24 & 30 \\
\hline No feedback & 0 & 0 & 16 & 20 \\
\hline
\end{tabular}

* There is more than one answer.

In relation to establishing an atmosphere of cooperation and ing, none in the control group were satisfied while all and helping other students, developing interpersonal relation- almost all 100\%, 97.5\% \& 95\% respectively of the intervenships, and developing a sense of responsibility for peer learn- tion students were satisfied. 
Table 5. Students' satisfaction regarding traditional and peer learning method used for both control and intervention group

\begin{tabular}{|c|c|c|c|c|c|c|c|c|}
\hline \multirow{3}{*}{$\begin{array}{l}\text { Learning method used } \\
\text { Provided a continuous feedback about your } \\
\text { performance }\end{array}$} & \multicolumn{4}{|c|}{$\begin{array}{l}\text { Intervention Group } \\
(\mathbf{n}=\mathbf{8 0})\end{array}$} & \multicolumn{4}{|c|}{$\begin{array}{l}\text { Control Group } \\
(n=80)\end{array}$} \\
\hline & \multicolumn{2}{|c|}{ Satisfied } & \multicolumn{2}{|c|}{ Dissatisfied } & \multicolumn{2}{|c|}{ Satisfied } & \multicolumn{2}{|c|}{ Dissatisfied } \\
\hline & 80 & 100.0 & 0 & 0.0 & 6 & 7.5 & 74 & 92.5 \\
\hline Developed responsibility for your peer's learning & 76 & 100.0 & 4 & 5.0 & 0 & 0.0 & 80 & 100.0 \\
\hline Promoted student-teacher interaction & 80 & 100.0 & 0 & 0.0 & 8 & 10.0 & 72 & 90.0 \\
\hline $\begin{array}{l}\text { Established an atmosphere of cooperation and } \\
\text { helping other students }\end{array}$ & 80 & 100.0 & 0 & 0.0 & 0 & 0.0 & 80 & 100.0 \\
\hline Developed interpersonal relationships & 78 & 100.0 & 2 & 2.5 & 0 & 0.0 & 80 & 100.0 \\
\hline $\begin{array}{l}\text { Created environments to practice building } \\
\text { leadership skills }\end{array}$ & 76 & 95.0 & 4 & 5.0 & 4 & 5.0 & 76 & 95.0 \\
\hline Created a cheerful environment toward learning & 80 & 100.0 & 0 & 0.0 & 6 & 7.5 & 74 & 92.5 \\
\hline Increased your interest toward Learning & 78 & 97.5 & 2 & 2.5 & 24 & 30.0 & 56 & 70.0 \\
\hline Made you concentrate more during learning & 80 & 100.0 & 0 & 0.0 & 44 & 55.0 & 36 & 45.0 \\
\hline Decreased your stress during Learning & 76 & 95.0 & 6 & 7.5 & 16 & 20.0 & 64 & 80.0 \\
\hline Chi square and $p$ & \multicolumn{8}{|c|}{$122.6 ; .001$} \\
\hline
\end{tabular}

As regards if the learning method used provided a continuous feedback, created a cheerful environment toward learning and created an environment to practice building leadership skills, only $7.5 \%, 7.5 \%$ \& $5 \%$ respectively of the control group students were satisfied while all and the most $100 \%$, $100 \%$ \& $95 \%$ of the students in the intervention respectively were satisfied.

Concerning the learning method used to promote studentteacher interaction only $10 \%$ of the control group was satisfied while all the students (100\%) in the intervention were satisfied. In relation to whether the learning method used increased the interest toward learning, 30\% of the control group were satisfied, while in the intervention $97.5 \%$ were not.

Regarding making students concentrate more, the table revealed that, more than half of the control group (55\%) were satisfied compared to all students $(100 \%)$ of the intervention. As regards whether the learning method used decrease stress during learning, it was observed that one-fifth $(20 \%)$ of the control group were satisfied compared to the most (95\%) of the intervention group. The difference between control and intervention group was found to be statistically significant $(p$ $=.000)$.

Figure 1 illustrates students' satisfaction level regarding traditional and Peer learning method used for both control and intervention groups. The figure demonstrates that only $10 \%$ of the students in the control group were satisfied with traditional learning while all students $(100 \%)$ in the intervention group were satisfied with peer learning.

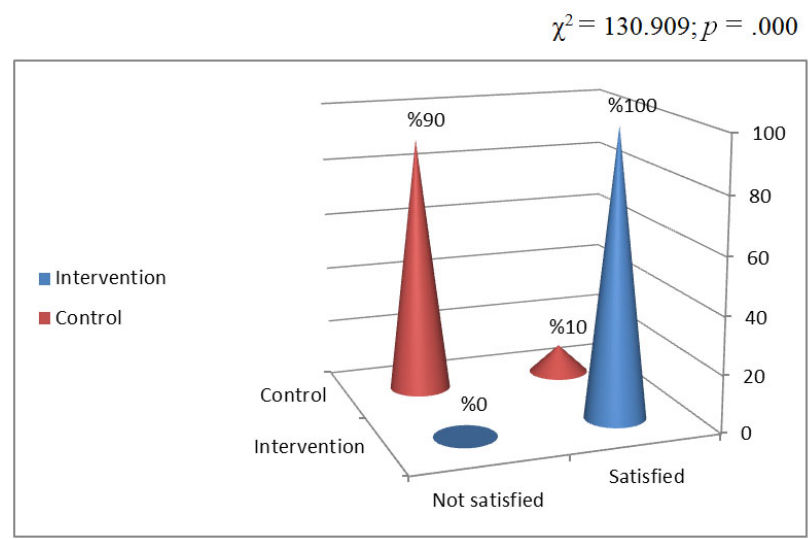

Figure 1. Students' satisfaction level regarding traditional and peer learning method used for both control and intervention groups

The difference between control and intervention groups concerning satisfaction level with learning method used was found to be statistically significant $\left(\chi^{2}=130.909, p=.000\right)$.

\section{Discussion}

Rapidly changing healthcare conditions necessitates the nurse educators to constantly assess and revise instructive curricula, approaches, and programs used to teach the new generation of nursing learners. What's more, utilizing innovative teaching strategies that would promote the evolution of nursing students' higher level of cognition as: critical thinking, decision making skills, communication skills, and clinical reasoning skills. The most advanced teaching strategies are concept mapping, discovery learning, simulation, problem based learning and peer learning. ${ }^{[20,21]}$ The present 
study aimed to determine the effect of application of peer learning strategy on obstetric and gynecological nursing students' clinical performance.

The present study results showed a highly significant difference $(p<.000 \%)$ in clinical performance between the two groups in favor of the peer learning after intervention. Where almost all of the intervention group got excellent degree as compared with only minority of the control group. This result suggests that peer teaching is effective in enhancing student clinical performance. In addition, multivariate analysis clarifies the independent impact of the peer learning strategy on students' performance scores in the five tested clinical procedures. This may be due to the fact that students are often able to explain a concept to another student in a unique way not used by the instructor.

This result is somewhat consistent with to the findings of several other researches. First, Wong et al. (2007) found that peer educator academic performance was enhanced. ${ }^{[22]}$ Second, Gözüm et al. (2010) recommended that peers can support learning through continuous contact. Peer education can be utilized to enhance early diagnosis of breast tumors and breast cancer attentiveness in asymptomatic females. ${ }^{[23]}$ Third, Bong et al. (2013) reported a significant considerable changes in information, attitude, self-efficacy, and intent to practice cervical cancer prevention behaviors. They further concluded that peer education program developed for Korean female college students was a beneficial and effective intervention strategy to encourage cervical cancer prevention behaviors in Korean sociocultural contexts. ${ }^{[24]}$

In addition, the result of the present study also in line with an Egyptian research done by El-Sayed et al. (2013), their findings indicated that nursing students who learned by peer teaching had performance score superior to that of those who were educated by assistant teaching staff in conventional clinical sessions. They had concluded that, the utilize of peer instruction in nursing education practical training is helpful for improving students' acquisition of skills with better performance, and for developing their teaching capacities, which are indispensable part of their future nursing role. ${ }^{[25]}$ Another Egyptian study done by Salama et al. (2013) had reported an improvement in total knowledge and in practice score post education. Where, the performance of breast selfexamination improved significantly after peer teaching $(p=$ .000). ${ }^{[26]}$

Moreover, the present finding is in accordance with an Egyptian study done by Battawi \& Abd elrazik (2014) as a part of Supporting of Excellence Students Projects (SESP) and under the supervision of combination of Ministry of Higher Education and Project Management Unit for Higher Education
Development (Phase III) at Faculty of Nursing, Alexandria University, Egypt. They found that, students enrolled in peer learning got higher marks and more satisfied in peer learning. Moreover students show more role accomplishment and more sharing in college activities. ${ }^{[27]}$

Such an agreement between the results of the current study $\&$ the results of the previously mentioned researches could through the light on the efficacy of peer teaching on students' performance. Such notion is explained by relevant literature. It states that peer education has expanded progress in learning outcomes and has implications for clinical practice. ${ }^{[28]}$

Peer learning is a kind of cooperative learning that promotes the value of students-students interaction and results in different advantageous learning outcomes. In relation to students' feedback on using peer learning strategy, it was found that almost all students prefer peer leaning method to learning nursing skills. These results may be due that, Peer Learning strategy encourages students to improve skills in organizing and planning learning activities, working cooperatively with others, giving and receiving feedback and evaluating their own learning. In addition it also helps to provide training leadership, improve confidence and intrinsic motivation, and may enhance an interest in academic careers. ${ }^{[29]}$

This finding is in line with a research conducted by Field et al. (2007), their results found that students have reported positively on the experience, particularly in developing confidence, knowledge and clinical skills. ${ }^{[29]}$ In addition, this finding was in congruence with the study conducted by Bawn (2007), he found that, students liked cooperative learning strategy more than traditional method. Students reported that cooperative learning increased their comfort and decreased stress during learning. ${ }^{[30]}$ Another study conducted by Alexander et al. (2008) mentioned that, peer learning encourages students to cooperate with each other, to promote students help, assist, support, encourage and praise their peers. ${ }^{[31]}$ Moreover, this is in agreement with the study done by Seifert et al (2009), their results showed that, nursing students had higher preference for cooperative learning strategies after practicing them in class. ${ }^{[32]}$

The present study revealed that all students (100\%) in the intervention group were satisfied with peer learning. while only $10 \%$ of the students in the control group. Statistically significant difference were found among control and intervention groups concerning satisfaction level.

This finding falls in line with the study of Lin et al. (2010), they found that there were significant differences in satisfaction with self-motivated learning and critical thinking among the groups ${ }^{[33]}$ In addition, this finding is also in conformity 
with the results of another study done by Stone et al. (2013), the study had concluded that nursing students could benefit from peer learning, with an increment in confidence and competence and a decline in anxiety. ${ }^{[34]}$

Moreover, the present study's result is also consistent with the findings of Andreesen et al. (2014), they found that the intervention group stressed on the role of the tutors as competent and well-trained teachers. Tutors motivate students, support them to incorporate into the ward team, and provide a non-fear-based working relationship whereby students' anxiety concerning working on ward decreases. ${ }^{[35]}$

Furthermore, this result is in accordance with the findings of of Sabaq et al. (2016), their results showed that the majority of peer teaching students, had less worried while performing lab skill, and more communicative $\&$ interactive with different students as well as received truthful feedback. ${ }^{[36]}$

Such similarities among the results of the above mentioned studies could be attributed to that all study subjects were adolescents with the same age group. In addition they had been used in the clinical setting either nursing or medical.

On the contrary with this present study result, Mills et al. $(2014)^{[37]}$ found that there were no difference in satisfaction between the study and control groups. Where, learners were highly satisfied with the instruction session with no difference in satisfaction scores found among those sessions educated by peers, clinical and non-clinical staff members.

\section{Limitation of the study}

Some limitations of this study were recognized. Small sample and it was difficult to have them generalize findings to all of nursing education. The study was done in clinical skills labs only and need to be applied in an actual clinical setting in a hospital unit.

\section{CONCLUSIONS AND RECOMMENDATIONS}

It can be concluded from the present study that peer learning strategy is an efficacious strategy in improvement of nursing students' performance.

There was a statistically significant difference in clinical performance scores concerning the five tested obstetric and gynecological clinical procedures among the study and control group after the intervention.

Accordingly, the study hypothesis was accepted.

Based on the findings of the present study, the following are recommended:

(1) Implementation of peer learning strategies is suggested in both classrooms and clinical settings to increase students' knowledge level and clinical performance.

(2) Seminars and training workshops are recommended to be conducted for nurse educators to increase their competencies in applying peer learning as a teaching strategy in the clinical teaching.

(3) Enough time should be allotted for all students to practice the procedure until they reaches competency level.

Recommendation for further studies:

(1) Replication with a larger sample to further validate the results.

(2) Conduct peer leaning strategy in other clinical teaching situations and using other cooperative learning models.

(3) Comparative study to determine the effect of traditional learning versus peer learning on students' social interactions, leadership ability and academic outcome.

\section{CONFLicts OF INTEREST Disclosure}

The authors declare that there is no conflict of interest.

\section{REFERENCES}

[1] Shrader SR. Learner Empowerment-A Perspective The Internet TESL Journal. 2003.

[2] Melrose S. What Works? A Personal Account of Clinical Teaching Strategies in Nursing. Education for Health. 2004; 17(2): 236-239. PMid:15763767 https://doi.org/10.1080/13576280410001 711067

[3] Nilsson K, Stomberg M. Nursing students' motivation toward their studies-a survey study. BMC Nursing, licensee Bio Med Central Ltd. 2008; 7-8 p.

[4] Mesler L. Making retention count: The power of becoming a peer tutor. Journal of Teachers College Record. 2009; 111(8): 1894-1915.

[5] Parkin V. Peer education: the nursing experience. Journal of Continuing Education in Nursing. 2006; 37(6): 257-264. https ://doi .or

Published by Sciedu Press g/10.3928/00220124-20061101-04

[6] Okoye Assumpta Amaka. Effect of Peer Tutoring Method on Students Academic Achievement in Home Economics. Academic Journal of Interdisciplinary Studie. July 2013.

[7] Oermann M. Using active learning in lecture: Best of both worlds. International Journal of Nursing Scholarship. 2004; 1(1): 1-9.

[8] Topping K, Ehly S. Peer assisted learning 2nd ed. London: Lawrence Erlbaum Associates, Inc, 2009.

[9] Thurston A. Topping K. Peer tutoring in schools: Cognitive models and organisational typography. Journal of Cognitive Education and Psychology. 2007; 6(3): 356-372. https://doi.org/10.1891/ 194589507787382070

[10] Cavallaro F, Tan K. Computer-mediated peer-to-peer mentoring. AACE Journal. 2006; 14(2): 129-138. 
[11] Liaw SS, Chen GD, Huang HM. Users' attitudes toward Web-based collaborative learning systems for knowledge management. Computers \& Education. 2008; 50(3): 950-961.

[12] Tiwari S, Lai P, So M, et al. A Comparison of problem based learning and lecturing on the development of students critical thinking. Medical Education. 2006; 40(6): 547-54. PMid:16700770 https://doi.org/10.1111/j.1365-2929.2006.02481.x

[13] Sally K. A Comparison of Student Outcomes Following Problem Based Learning Instruction versus Traditional Lectures Learning In A Graduate Pharmacy Course. Journal of the American Academy of Nurse Practitioners. 2003; 15(12): 550-58. https ://doi .org/10 $.1111 / j .1745-7599.2003 . t b 00347 . x$

[14] Cohen E. Restructuring the classroom; conditions for productive small groups. Review of educational research. 1994; 64(1): 1-35. https://doi.org/10.3102/00346543064001001

[15] O'Donnell M, King A. Cognitive perspectives on peer learning. Mahwah: lawwrence Erlbaum associates Publisher. 1999; 14(2): 87-90.

[16] Topping K, Bryce A. Crossage peer tutoring of reading and thinking: influence on thinking skills. Journal of Educational Psychology. 2005; 24: 595-621.

[17] Secomb J. A systematic review of peer teaching and learning in clinical education. Journal of Clinical Nursing. 2008; 17(6): 703-716. PMid:18047577 https : //doi .org/10.1111/j.1365-2702 . 20 $07.01954 . \mathrm{x}$

[18] Goldsmith M, Stewart L, Ferguson L. Peer learning partnership: An innovative strategy to enhance skill acquisition in nursing students. Journal of Nurse Education Today. 2006; 26(2): 123-130. PMid:16202483 https://doi.org/10.1016/j.nedt.2005.08 .001

[19] Loke AJ, Chow FL. Learning Partnership The Experience of Peer Tutoring Among Nursing Students: A qualitative Study. Int J Nurs Stud. 2007; 44(2): 237-244. PMid:16412444 https://doi.org/ 10.1016/j.ijnurstu.2005.11.028

[20] Bradshaw M, Lowenstein A. Innovative teaching strategies in nursing and related health professions. 6th ed. United States of America: Jones \& Bartlett Learning Co. 2014; 6-10.

[21] Tinnon E. Scavenger hunt: A creative teaching strategy to introduce pharmacological concepts and ethical concerns. Teaching and Learning in Nursing. 2014; 9(3): 104-7. https : //doi .org/10.1016/j. teln.2014.03.004

[22] Wong JG, Waldrep TD, Smith TG. Formal peer-teaching in medical school improves academic performance: the MUSC supplemental instructor program. Teach Learn Med. 2007; 19(3): 216-220. PMid:17594215 https : //doi.org/10.1080/10401330701364 551

[23] Gözüm S, Karayurt O, Kav S, et al. Effectiveness of peer education for breast cancer screening and health beliefs in eastern Turkey. Cancer Nurs. 2010 May-Jun; 33(3): 213-20. PMid:20357655 https : //doi.org/10.1097/NCC.0b013e3181cb40a8

[24] Bong C , Hyun Suk M, Jin Sun K. Effects of a Peer Cervical Cancer Prevention Education Program on Korean Female College Students'
Knowledge, Attitude, Self-efficacy, and Intention. Korean Jounal of Adult Nursing. 2013; 25(6): 736-746.

[25] El-Sayed S. Effect of peer teaching on the performance of undergraduate nursing students enrolled in nursing administration course. Journal of Nursing Education and Practice. 2013; 3(9): 156-166. https://doi.org/10.5430/jnep.v3n9p156

[26] Salama H, Elsebai H, Abdelfatah F, et al. Effects of Peer Education on the Knowledge of Breast Cancer and Practice of Breast SelfExamination among Mansoura University Female Students Journal of American Science. 2013; 9(10).

[27] Battawi J, Abd elrazik A. Supporting of excellence students projects (SESP) and under the supervision of combination of Ministry of Higher Education and Project Management Unit for Higher Education Development (Phase III) at Faculty of Nursing, Alexandria University, Egypt. 2014.

[28] Ten Cate O, Durning S. Dimensions and psychology of peer teaching in medical education. Med Teach. 2007; 29(6): 546-552. PMid:17978967 https ://doi.org/10.1080/01421590701583 816

[29] Field M, Burke JM, McAllister D, et al. Peer-assisted learning: a novel approach to clinical skills learning for medical students. Med Educ. 2007; 41: 411-418. PMid:17430287 https://doi.org/10 $.1111 / j .1365-2929.2007 .02713 . x$

[30] Bawn S. The effects of cooperative learning on learning and engagement. Master in Teaching. Project to the Faculty of the Evergreen State College. 2007.

[31] Alexander BJ, Pharm D, Lindow LE, et al. Measuring the impact of cooperative learning exercises on student perceptions of peer-to peer learning: a case study. J Physician Assist Educ. 2008; 19(3): 18-25. https://doi.org/10.1097/01367895-200819030-00005

[32] Seifert K, Fenster A, Dilts J, et al. An investigative, cooperative learning approach to the general microbiology laboratory. Life Sciences Education. 2009; 8(2): 147-53.

[33] Lin CF, Lu MS, Chung CC, et al. A comparison of problembased learning and conventional teaching in nursing ethics education. Nurs Ethics. 2010; 17: 373-382. PMid:20444778 https : //doi.org/10.1177/0969733009355380

[34] Stone R, Cooper S, Cant R. The value of peer learning in undergraduate nursing education: A Systematic Review . Hindawi Publishing Corporation. 2012.

[35] Andreesen S, Köhl-Hackert N, Hoffmann K, et al. Cross-year peer tutoring on internal medicine wards: results of a qualitative focus group analysis. Adv Med Educ Pract. September 2014 ; 23(5): 323-30.

[36] Sabaq A, Farouk M, Ismail S. Effect of peer teaching versus traditional teaching method on nursing students performance regarding pediatric cardio pulmonary resuscitation. IOSR Journal of Nursing and Health Science. 2016; 5(2): 18-25.

[37] Mills J, Dalley water W, Tischler V. An assessment of student satisfaction with peer teaching of clinical communication skills. BMC Medical Education. October 2014; 14: 217. 